\title{
Performance Quality and Long -Term Objectives, Educational Services and Priorities in Albanian Administrative Reforms
}

\author{
Prof Ass Dr. Alba Robert Dumi
}

Prof As Dr, Dean of Graduated School"Ismail Qemali" VIora University Albania,

\section{Ma Emine Emurllai}

PhD Candidate SEEU University, Public Administration Faculty, Macedonia

Email: ee12266@seeu.edu.mk

\author{
Ma Gladiola Jazaj \\ Management Department, Economy Faculty, Tirana University \\ Email:besi.alba@yahoo.com
}

\section{Doi:10.5901/ajis.2013.v2n2p167}

\section{Abstract}

\begin{abstract}
The purpose of this paper research is the national educational service is to supply future Albanian citizens with proper knowledge, adequate skills and capacities, as to be educated and committed to the implementation of the economic and development national plan. This system, aiming to meet the domestic needs of the labor market and socio-cultural aspirations of the people, is a prerequisite for the economic growth and sustainable development of the country. Fulfillment of mid-term and long-term objectives in view of the stable economic growth, reduction of poverty and resolution of social problems require, first and foremost, the reform of the educational system as the genuine support to the implementation of governmental initiatives. The National Strategy on University Education stipulates short-term and mid-term objectives and goals for the system and introduces policies on strategic priorities for the following years until 2013. The concept of evaluation must be considered as a psycho-social and administrative process which has its own impacts on the motivation and performance of the public administration. The right relations between them, increase of the evaluation criteria, the combination of the evaluation of individual performance with the respective structure as a strong bond of evaluation and career, use of the method of selfevaluation, evaluation for your superior and your colleague, financial rewards etc, are not only the success of the administration but also guarantee a qualitative management.
\end{abstract}

Keywords: Educational services, national strategy, individual performance,merits, qualitative management.

\section{Introduction}

At the beginning of the ' 90 the role of the Albanian state was modernized, and was stimulated to economic improvement and to conceal social injustice. The new role of the state determined new obligations for the public, central and local administration. During this period the administration was nearly totally politicized and there were no clear divisions between the political and techno-professional functions. During this period the model of the political control was inappropriate and out of logic and it was still in the development phase.

During 1996-1999 the politicization of the administration ended and the administration was based on merits. The division between the political and techno-professional was clear. Several laws were approves; law no. 8095 in 21.03.96, "For the Civil Service in the Albanian Republic", The Decision of the Minister's Council no.657 in 16.09 .96 "For ethic rules in the public service", law no. 8549 in 11.11.1999 "The status of the civil employee". All this laws were approved during this period. The administration had the possibility to implement a different system, in the human resources management in all the central and local institutions. After DAP, the Institution of Training for the Public Administration was funded in order to give response to all the circumstances, opportunities and to the new challenges. The strategy includes school education, primary and secondary education, general secondary education and professional education, The professional 
education during the following decade must carry out a regular reform intended to change SE into a capable system to adapt to the continuously changing labor market. This reform goes beyond the merely institutional improvements up to radical changes in the vision, attitudes and conduct of all committed stakeholders

\subsection{Decision making and Decentralization}

Decentralization of the educational sector shall ensure the extension of participation and increase of the effectiveness of groups of interest in the outline of educational projects and their implementation. This process shall be carried out through a proper balance between the centralization and decentralization, being accompanied by the public awareness of potential risks and chances of successThe Employees, Lectors, Proffessors as humans was "discovered" in the 1930s with the human relations school.

\subsubsection{What is continuous quality improvement (CQI)?}

Continuous Quality Improvement (CQI) is:

- A theory-based management system that looks at processes/outcomes

- Culture change

- Client-centered philosophy

- Tools to help quantify what we do

- A search for common causes of variation

- Driven by data

- System, process and client feedback

- Shared success

- Long-term approach

What are the Key Elements of Continuous Quality Improvement?

- Accountability

- Driven by good management...not crisis

- Driven by input from all levels of staff and stakeholders

- Teamwork

- Continuous review of progress

- The organization's leadership promotes a culture that values service quality and continual efforts by the full agency, its partners, and contractors to achieve strong performance, program goals, and positive results for service recipients.

\subsection{The process of working students, long term policies.}

The whole process involves all the working students in University auditorium, learning, express innovative ideas, conducting their project in their classes, in order to show up their achievement during the teaching process. Acknowledged development strategies given by the teacher and the evaluation of student scientific projects. The Strategy is in line with the main development trends of education in Europe and in the world, aiming to adopt the development of university education to the governmental vision for mid-term and long-term policies of the sector. It incorporates the suggestions of the academic community and of the groups of interest within the country. The strategy represents the pillar of an Action Plan with tasks scheduled to be implemented until 2013.

Process1: Teaching methodology, this process of implementing this strategy, the leadership role is based on rules and extreme strict responsibilities toward the students, in order to handle the unexpected difficulties and obstacles the work of all the students to achieve their goals and purposes. (De Bruijn, H. 2002)

Process 2: The second definition of HRM encompasses the management of people in organizations from a macro perspective i.e. managing people in the form of a collective relationship between management and employees. The infrastructure that supports performance and quality improvement is sufficient to identify organization-wide issues, implement solutions that improve overall productivity, and promote accessible, effective services in all regions and sites. 
- An inclusive approach to establishing measured performance goals and client outcomes, indicators, and sources of data ensures broad based support for useful performance and outcomes measurement.

\section{Literature Review and Hypotheses}

Reports, with findings based on improvement efforts, are issued periodically to personnel throughout the agency and provide information useful for improving programs and practice.The Performance and Quality Improvement plan describes how valid, reliable data will be obtained and used on a regular basis to advance monitoring of actual versus desired: functioning of operations, that influence the organization's capacity to deliver services;

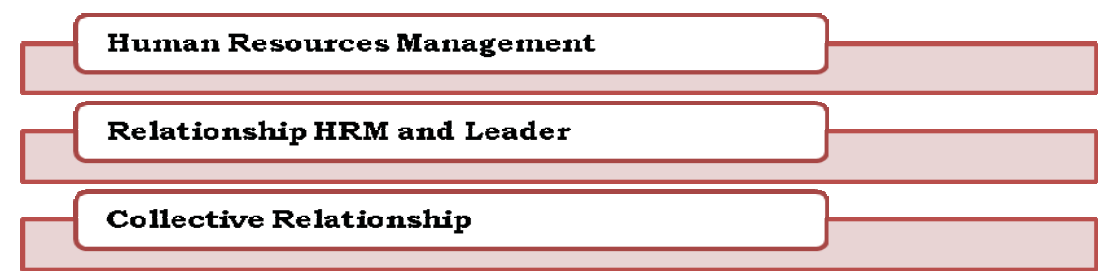

Employee Satisfaction Survey Results and Indicators, Dumi A MJSS, Vol 3 nr 11

The indicators of the questionaries is: The quality of service+ The program results+ The client satisfaction+ The operators and client outcomes

The quality of service delivery; "I feel my work is helpful in protecting children and helping families".15 (2\%) 20 (2\%) 53 (6\%) 400 (42\%) 474 (49\%)

The program results; "I am given the resources to do my job well". 55 (6\%) 236 (25\%) 97 (10\%) 458 (48\%) 116 $(12 \%)$

The client satisfaction; "I receive recognition and lappreciation for the job I do it".105 (11\%) 233 (24\%) 105 (11\%) 394 (41\%) 125 (13\%)

The operators and client outcomes" My workload allows me to give enough attention to each one of my responsibilities". 240 (25\%) 323 (34\%) 90 (9\%) 278 (29\%) 31 (3\%)

\subsection{Staff training and support}

Staff and stakeholders receive training and support that increases their capacity to participate in, conduct, and sustain performance and quality improvement activities. This approach focuses on the objectives and outcomes of the HRM function. What this means is that the HR function in contemporary organizations is concerned with the notions of people enabling, people development and a focus on making the "employment relationship" ful-filling for both the management and employees. (Selznick, Philip. 1957) These definitions emphasize the difference between Personnel Management as defined in the second paragraph and human resource management as described in the third paragraph. (Robbins, S.P. 1998).To put it in one sentence, personnel management is essentially "work-force" centered whereas human resource management is "resource" centered. The key difference is HRM in recent times is about fulfilling management objectives of providing and deploying people and a greater emphasis on planning, monitoring and control. (De Bruijn, H. 2002)

\subsection{Analyzing and reporting information}

The hypothesis coming next: Learning process is difficult, but if someone (students themselves) is not given what is meant hard to resolve, human being never knows how far reaches. Often in everyday life student-teacher relationship is mutual and the leadership responsibility is high Regardless to the specifics that takes the position of teacher relations, fundamental is to be perceived as work relationship which are characterized by tolerant communications that runs through good will of understanding and bon-sense. Tolerantia=Patience (a Latin word). An important aspect of our daily work and educational learning, where there should be tolerance and to show the full comprehension, the superlative degree is that of controlling student knowledge possession. Dumi A MJSS, vol $3, n r 11$ 
Cultural differences between nations can be, to some extent, described using first four and now five, bipolar dimensions. The position of a country on these dimensions allows us to make some predictions on the way their society operates, including their management processes and the kind of theories applicable to their management. As the word culture plays such an important role in my theory, let me give you my definition, which differs from some other very respectable definitions. Culture to me is the collective programming of the mind which distinguishes one group or category of people from another. In the part of my work I am referring to now, the category of people is the nation.

\subsection{Use and communication of qualityinformation to make improvements}

Culture is a construct that means it is "not directly accessible to observation but inferable from verbal statements and other behaviors and useful in predicting still other observable and measurable verbal and nonverbal behavior". It should not be reified; it is an auxiliary concept that should be used as long as it proves useful but bypassed where we can predict behaviors without it.

The some applies to the dimensions I introduced. They are constructs too that should not be reified. They do not "exist"; they are tools for analysis which may or may not clarify a situation. In my statistical analysis of empirical data the first four dimensions together explain 49 percent of the variance in the data. The other 51 percent remain specific to individual countries.

\section{Material and Methods}

The first four dimensions were initially detected through a comparison of the values of similar people (employees and managers) in 64 national subsidiaries of the IBM Corporation. People working for the same multinational, but in different countries, represent very well-matched samples from the populations of their countries, similar in all respects except nationality.

The first dimension is labelled Power Distance, and it can be defined as the degree of inequality among people which the population of a country considers as normal: from relatively equal (that is small power distance) to extremely unequal (large power distance). All societies are unequal, but some are more unequal than others.
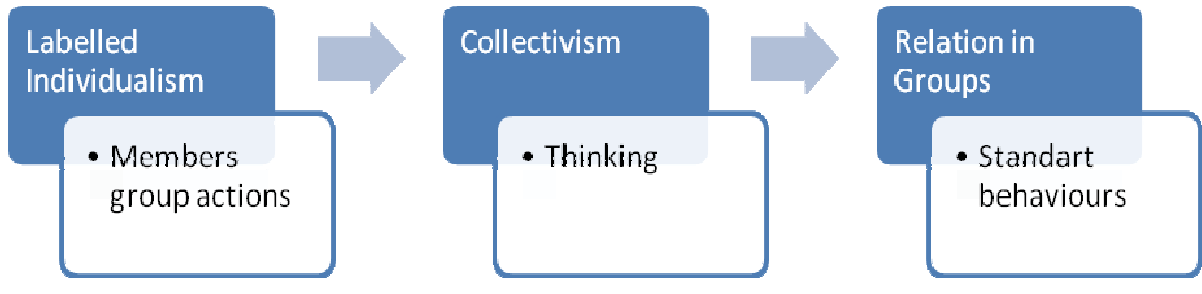

Figure 1: Bradler\& Sediss Individualism and organizational behavior The raport Company: Kingston, Ontario, 1989.

The second dimension is labelled Individualism and it is the degree to which people in a country prefer to act as individuals rather than as members of groups. The opposite of individualism can be called Collectivism, so collectivism is low individualism. The way I use the word it has no political connotations. The performance evaluation of the employees has two objectives: Administrative objectives.It gives information in setting the salary, promotions, firing, and assures the necessary documentation to verify decisions in juridical processes.

\subsection{Analyzing data}

The performance evaluation is mainly characterized by qualitative indicators and there are only a few quantitative indicators. According to the data collected from the questionnaires the employees asses the importance of the performance evaluation in $100 \%$, they concretize it with the objectivity in the evaluation. To the question "Is the 
performance evaluation objective in your institution?"- 30\% answered positively, $44 \%$ avoided the answer and $26 \%$ of them think that it is dictated from the subjectivity of the leaders. According to the questionnaire the major part of the questioned employees think that the performance evaluation takes to conflicts between the subordinate and the superiors. This is also another factor that contests rewarding according to the performance.

\subsection{Individualism and organizational behavior}

The third dimension is called Masculinity and its opposite pole Femininity. It is the degree to which tough values like assertiveness, performance, success and competition, which in nearly all societies are associated with the role of men prevail over tender values like the quality of life, maintaining warm personal relationships, service, care for the weak, and solidarity, which in nearly all societies are more associated with women's roles. Women's roles differ from men's roles in all countries; but in tough societies, the differences are larger than in tender ones.

\subsection{The performance evaluation and quantitative indicators. Development of objectives}

The performance evaluation is mainly characterized by qualitative indicators and there are only a few quantitative indicators. According to the data collected from the questionnaires the employees asses the importance of the performance evaluation in $100 \%$, they concretize it with the objectivity in the evaluation. To the question "Is the performance evaluation objective in your institution?"- $20 \%$ answered positively, $54 \%$ avoided the answer and $26 \%$ of them think that it is dictated from the subjectivity of the leaders. According to the questionnaire the major part of the questioned employees think that the performance evaluation takes to conflicts between the subordinate and the superiors.

\begin{tabular}{|c|c|c|c|}
\hline $\begin{array}{c}\text { CONSISTENCY OF THE } \\
\text { LEADER OBJECTIVES } \\
\text { (instructor) }\end{array}$ & TRADITIONAL CONCEPT & CONTEMPORARY CONCEPT & $\begin{array}{c}\text { EXPECTA } \\
\text { TIONS }\end{array}$ \\
\hline Teaching & Acquisition of knowledge & Coordination of knowledge & $60-70 \%$ \\
\hline Knowledge & Are they absolute..? & Knowledge built on consciously & $60 \%$ \\
\hline Students & $\begin{array}{c}\text { We all learn the same way and not all } \\
\text { are able to learn better. }\end{array}$ & $\begin{array}{c}\text { Different students learn in } \\
\text { different ways but not all are } \\
\text { able to learn. }\end{array}$ & $60 \%$ \\
\hline
\end{tabular}

Tab 1: Traditional concept, Staffing, Payroll, Social and multicultural influences, Higgins 1983

This is also another factor that contests rewarding according to the performance. (Higgins, J.1983) State-funded Higher Education Institutions are autonomous. Autonomy might be described as freedom for higher education institutions to run their own affairs, in particular in relation to staff, students, curricula (teaching and examining), governance, finance and administration.

The following issues are relevant in the allocation of funding to higher education institutions: 1 .Negotiation on the basis of an estimate from the institution, 2.Fixed on the basis of past costs, Performance indicators play a role in funding allocations. Research is funded separately.

\section{Finding and Results of this paper research}

The following accountability measures apply and they are mandatory: 1. External financial audit,2. Internal financial audit, the main objective is the objective of the development. The information can be used to diagnose the needs for trainings, career planning etc. the feedback and the training based on the information of the evaluation assures the fundaments for constant performance improvement. (Robins \& Couter, 1999) The question "Is the performance evaluation objective?" was analyzed in details and the answers were evaluated from 1-10 points each, nine of the questioned persons were leaders and employees.

The respective evaluations are presented below: 


\begin{tabular}{|c|c|c|c|c|c|}
\hline First choice & 7 & 8 & 7 & 9 & 10 \\
\hline Second choice & $4 \& 3,45$ & $7 \& 3,56$ & $5 \& 4.78$ & $6 \& 4.78$ & $4 \& 4.71$ \\
\hline
\end{tabular}

The performance evaluation is determined as an evaluation of the past and actual performance of an employee that works in accordance with the performance standards of the organization. In fact, most organizations have different departments dealing with Staffing, Payroll, and Retention etc. Instead, the HR manager is responsible for managing employee expectations vis-à-vis the management objectives and reconciling both to ensure employee fulfillment and realization of management objectives. (Glueck, W.F. and Jauch, 1986)

It means that our economy and our state have defined the path of development 292 priorities. It also means that these sectors, defined as priority ones, will be as a focus of the controlled developments and orientation and promotion policies. (Goffin Robert 2001)

We calculate the sum of the first choice and the average

$$
\begin{aligned}
& \mathrm{R}_{10}=6+7+8+9 \\
& \mathrm{M}_{\mathrm{R}}=\frac{\frac{\mathrm{n} 1(\mathrm{n} 1+n 2+1)}{2}=\frac{4(4+\Sigma+1)}{2}=20}{2}
\end{aligned}
$$

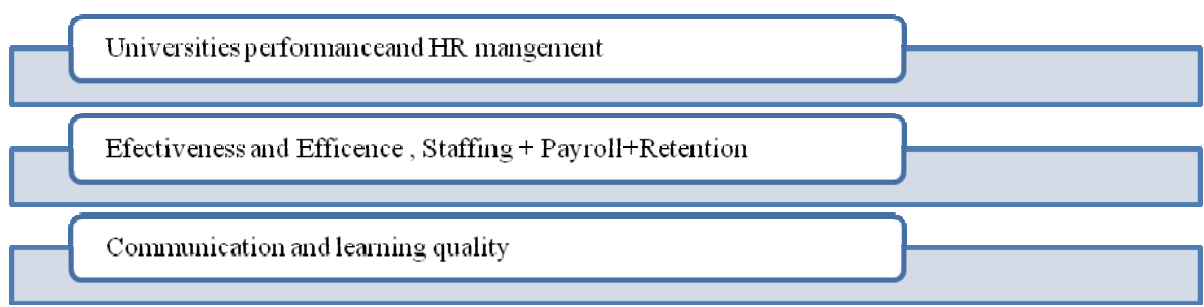

Meanwhile, it remains relevant to discuss whether the Albanian financial system has the same priorities or not. Are the directions of the priorities of the economic sectors harmonized with the directions of the financial system? If the answer were yes, this would be evidence to a development and progress in the right direction. If not, we need to make the necessary adjustments. While leadership researchers have emphasized that managers need to vary the performance of their leadership functions depending on characteristics of their followers, the task, the organizational culture, their position power, and other factors, they have commonly equated followers with subordinates. (Zvi and Merton 2002)

The research presented in this paper has taken a distinctly different approach and examined the leadership behaviors of two groups of managers in their interactions with the members of their superiors and peers, in addition to their subordinates. The argument was made that in order for managers to be effective leaders in their interactions with their subordinates, peers, and superiors, they need to have a broad repertoire of leadership functions at their disposal as well the ability to vary the performance of these leadership functions depending on the organizations role of the person with whom they interact.

\section{Conclusions and Recommendations}

The governance in education, particularly in terms of the decentralization represents an urgentneed to be developed in accordance with the current standards. In a general perspective, the application of a too centralized management level in the nationalgovernance in general and in the area of services in particular, leads to the reduction of effectiveness and efficiency of the public administration. Decentralization of the system of management and servicesis a key component of the broader decentralization process undertaken in Albania.While formal restructuring toward the decentralization has marked significant progress in several sectors, including the sector of education, the progress of the decentralization of responsibilities and of the decision making authority from central to local level for the pre-university education has not been satisfactory.

First, there is a lack of the full operational link of the school with the community as a democratic obligation to provide good education to everyone. There is a lack of encouragement of the power of the family for the social character 
of the community, to fully invest efforts in the area ofeducation. This is based on the inadequate level of participation and the responsibility of all stakeholders.

The consequences are present in respect of the malfunctioning failing to meet the needs and requirements of the community of educational leadership, school management, contents of curricula, financial planning and management, school maintenance, personnelmanagement to offer a modern educational service and discharge the integrating function of schools.

Reform and strengthening of policy making, management and decision making capacity is one of the priorities in the framework of the European Partnership according to which: "The government is committed to realize the school autonomy through the educational reform in cooperation with the groups of interest"

At central level: Restructuring of the Ministry of Education and Science and subordinate institutions by building a clear management performance- based scheme.

At regional level: Restructuring of the Regional Educational Directorates and Educational Offices in view of further developing capacities in support of schools.

In the framework of decentralization: Decentralization and delegation of responsibilities and of decision making authority from central to local governance level.

At school level: Realization of school autonomy in the area of subject programs, financing, personnel and management at school level and above, completing it with the legal basis and respective implementing bodies.Development of policies and launching of research based and data oriented central, local and school decisions: Functioning of the information management system in the area of education.

\section{References}

Albanian Progress Raport 2013" Economy reforming and development', pp 4, 21

Albanian Raport" Reform and strengthening of policy making" 2012, pp 8,11, 45

Albanian government for educational priorities, report $2010 \mathrm{pg} 12,25,41,58,74$

Bodie Zvi (Nobelist), "Educational reforming strategy" Merton Robert, Finance, (2002), foreword from Paul Samuelson, Nobelist.

A lba Dumi 2012, The role of university in reformin of public sector, in Academic Journal of Interdisciplinary Studies, pp 135

Bishop, E. B. "ROCE as s Tool for Planning and Contol", Long Range Planning, 2, 4, 1969, 80-7

Bradler\& Sediss The raport Company: Kingston, Ontario, 1989

Egamberdi, Nilufar; Center for Economic and Social European Communities, L175, pages 40-48 "

Glueck, W.F. and Jauch, L. R. Business Policy and Strategic Management, 4th, edn, McGraw-Hill, New york, 1984

Higgins, J. M. 1983Organizational Plicy and Starategic Management strategy $2^{\text {nd }}$ edn, Dryden New York,

Hofer, C, W. and Schendel, D 1983, Dtrategy Formulation: Analytical Concepts, West, St Paul,

Industrial Performance Analysis, 1987-1988 edn, ICC Business Policy and Management Capacity,2nd edn Irwin, Homewood, IL,1985.

Tilles, S. "How to Evaluate Corporate Strategy", Harvard Business Review, 41,4, 111-21.

Organizational Management "Departament of the Environment, London 1990.De Soto, Hermine; Overseas Private Investment Corporation, 1100 New York Ave., NW Washington, The assessmentof the affects of certain public and private projects on the environment', pg 123-129

Leung, Hok Lin. Land Use Planning Made Plain Ronald Fruye 
